\title{
Evidence for Nearly Complete Decoupling of Very Stable Nocturnal Boundary Layer Overland
}

\author{
Yu Xia • Franz Conen • Laszlo Haszpra • \\ Zita Ferenczi · Wlodek Zahorowski
}

Received: 19 April 2010 / Accepted: 30 September 2010 / Published online: 24 October 2010

(C) Springer Science+Business Media B.V. 2010

\begin{abstract}
Concentrations of ${ }^{222} \mathrm{Rn}$ at $0.1 \mathrm{~m}$ and $6.5 \mathrm{~m}$ height above ground level and ${ }^{222} \mathrm{Rn}$ flux density were measured during nights characterized by strong cooling, light winds and clear sky conditions in the Carpathian Basin in Hungary. A very stable boundary layer (vSBL) formed on 14 nights between 15 August and 3 September 2009. On 12 nights, an estimated $72 \%$ (s.d. 20\%) of ${ }^{222} \mathrm{Rn}$ emitted from the surface since sunset was retained within the lowest $6.5 \mathrm{~m}$ above the ground until sunrise the following morning. On two nights an intermittent increase in wind speed at $9.4 \mathrm{~m}$ height was followed by a rise in temperature at $2.0 \mathrm{~m}$ height, indicating a larger atmospheric motion that resulted in ${ }^{222} \mathrm{Rn}$ at $0.1 \mathrm{~m}$ around sunrise being the same as around the preceding sunset. It does not seem to be rare in a large continental basin for a vSBL to be nearly completely decoupled from the atmosphere above for the entire period from sunset to sunrise.
\end{abstract}

Keywords Decoupling · Radon · Tracer experiment - Very stable nocturnal boundary layer

\section{Introduction}

Shortly before sunset, thermals in the convectively mixed boundary layer fade away. Radiative heat loss from the surface stabilizes a shallow layer of cooling air that is in direct contact with the ground (Malhi 1995; Oyha et al. 1997; Mahrt 1998), and in light wind, clear-sky

Y. Xia $(\bowtie) \cdot$ F. Conen

Institute of Environmental Geosciences, University of Basel, Bernoullistrasse 30, 4056 Basel,

Switzerland

e-mail:yu.xia@unibas.ch

L. Haszpra $\cdot$ Z. Ferenczi

Hungarian Meteorological Service, P.O. Box 39, Budapest 1675, Hungary

W. Zahorowski

Australian Nuclear Science and Technology Organization,

Locked Bag 2001, Kirrawee DC, NSW 2232, Australia 
conditions, large temperature gradients develop that severely suppress turbulent mixing and lead to the formation of a very stable boundary layer (vSBL). Mahrt (1998) demonstrated the breakdown of existing turbulence formulations under such conditions, where meandering and other mesoscale motions add to the elusiveness of the situation. Structure and dynamics of a stable nocturnal boundary layer are determined by complex interactions between the static stability of the atmosphere and such mesoscale motions that intermittently generate mechanical turbulence (Stull 1988; Sun et al. 2004). Variations in these processes in time and space at different heights and scales make it very difficult to predict transport pathways and diffusion of pollutants (Beyrich 1994; Bowen et al. 2000; Salmond and McKendry 2005).

Banta et al. (2007) found the vSBL to be isolated and decoupled from the atmosphere above for several hours by the presence of what they termed a quiescent layer. This implies that pollutants, or any other gaseous or particulate emissions from near the surface, may be quantitatively conserved in the vSBL for prolonged periods at night. It seems to us that only a tracer experiment is able to convincingly demonstrate a prolonged decoupling of near-surface air from the atmosphere above. Serendipitously, we identified a number of such decoupling events while estimating non- $\mathrm{CO}_{2}$ greenhouse gas emissions in the Carpathian Basin by a mass balance approach with ${ }^{222} \mathrm{Rn}$, such as was done before in Japan (Moriizumi et al. 1996), Australia (Wilson et al. 1997), Switzerland (Conen et al. 2002) and many other parts of the world. All land surfaces naturally emit the radioactive noble gas ${ }^{222} \mathrm{Rn}$ to the atmosphere where it is lost by decay (half lifetime of 3.82 days). Measurements of ${ }^{222} \mathrm{Rn}$ concentrations are usually made at a single height above the ground.

Our experimental set-up included two measurement heights that were both well within the vSBL, since at both levels we saw substantial increases in ${ }^{222} \mathrm{Rn}$ concentration during the whole night. Since we also measured ${ }^{222} \mathrm{Rn}$ flux density, we were able to determine with some confidence the proportion of emitted ${ }^{222} \mathrm{Rn}$ that accumulated between sunset and sunrise in the vSBL. A shortcoming associated with the unexpectedness of our observations is the lack of high frequency three-dimensional wind data, and temperature measurements performed at only one height. This does not compromise our ${ }^{222} \mathrm{Rn}$ budget of the vSBL or its testimony of prolonged decoupling, but limits meteorological analysis of the 14 nights that we present.

\section{Material and Methods}

Observations were made at K-puszta, a regional background air pollution monitoring station $\left(46^{\circ} 58^{\prime} \mathrm{N}, 19^{\circ} 33^{\prime} \mathrm{E}, 125 \mathrm{~m}\right.$ above sea level), located in a sparsely grass covered clearing of about $10^{4} \mathrm{~m}^{2}$ in a mixed forest reserve, about $45 \mathrm{~km}$ east of the Danube river, on the Hungarian Great Plain in the middle of the Carpathian Basin. The maximum difference in elevation between the 10 geodesic points within a radius of $5 \mathrm{~km}$ is $11.3 \mathrm{~m}$. The larger elevations are in the north-east, the smaller in the south-west part of this circle. Immediately surrounding the clearance are plots dominated by pine (Pinus sp.), mostly between 3 and $5 \mathrm{~m}$ tall. Soils are sandy and poor and so is plant growth. Intermediate surroundings include large plots that have been cleared for re-planting. Land use outside a radius of about 2 to $3 \mathrm{~km}$ is dominated by row crops and grazing. The region is climatologically calm and characterised by intensive solar radiation during summer (Haszpra 1998). Prevailing winds are from the north-west and the annual average scalar wind speed for the past decade is $2.3 \mathrm{~m} \mathrm{~s}^{-1}$ at $9.4 \mathrm{~m}$ above the ground according to the database of the Hungarian Meteorological Service. The station is part of the Global Atmospheric Watch (GAW) network and the European Monitoring and Evaluation Programme (EMEP). Meteorological parameters measured at the station include, among others, hourly air temperature at $2.0 \mathrm{~m}$ height, scalar averaged wind speed at $9.4 \mathrm{~m}$ 
height and global radiation. The site characteristics are conducive to the development of the vSBL. If a vSBL was isolated from the atmosphere by what Banta et al. (2007) call a quiescent layer, which may numerically be represented by a free-slip layer preventing the exchange of trace species between the vSBL and the atmosphere above, then all the ${ }^{222} \mathrm{Rn}$ emitted should accumulate within the vSBL so long as stability is not disturbed.

Atmospheric ${ }^{222} \mathrm{Rn}$ concentrations were measured continuously at a height of $6.5 \mathrm{~m}$ with a $0.700 \mathrm{~m}^{3}$ dual-flow loop, two-filter detector as described in Whittlestone and Zahorowski (1998); the detector was built at the Australian Nuclear Science and Technology Organisation (ANSTO). At a height of $0.1 \mathrm{~m}$ above the surface, and $15 \mathrm{~m}$ north-north-west of the measurements at $6.5 \mathrm{~m}$ height, ${ }^{222} \mathrm{Rn}$ concentrations were determined by a small ionisation chamber (AlphaGUARD PQ 2000Pro, Genitron Instruments, Frankfurt, Germany). This instrument is less sensitive than the ANSTO detector but useful for near-surface concentration measurements and for determining ${ }^{222} \mathrm{Rn}$ flux density with accumulation chambers (Lehmann et al. 2001 , 2004). Both detectors measure ${ }^{222} \mathrm{Rn}$, not the progeny, and both have been calibrated to standards traceable to the National Institute of Standards and Technology (NIST). Parallel measurements at the same height have yielded similar results. The small ionisation chamber was continuously flushed with air $\left(1.4 \times 10^{-5} \mathrm{~m}^{3} \mathrm{~s}^{-1}\right)$ aspired through an inlet at $0.10 \mathrm{~m}$ above the soil surface and located within a $0.23-\mathrm{m}$ diameter open-top plastic collar, which extended $0.17 \mathrm{~m}$ above and $0.10 \mathrm{~m}$ below the soil surface. The few shoots of grass growing inside the collar were regularly removed. Aspirated air was continuously returned via an outlet tube into the same collar. The collar was opened each day during six time intervals of $2.5 \mathrm{~h}$ duration. During these intervals ambient air was flushed through the ionization chamber and ${ }^{222} \mathrm{Rn}$ decay was counted. The top of the collar was closed in between these intervals by a rotating shutter for $1.5 \mathrm{~h}$ intervals to determine the ${ }^{222} \mathrm{Rn}$ flux density.

The time reference for all reported measurements is UTC, and all measured quantities are one-hourly means. Time stamps are at the end of an integration period. Instruments operated, with some interruptions, from the end of March to the end of September 2009; the period from 15 August to 2 September has been selected for analysis. Nights are referred to by the date marking their end.

\section{Results and Discussion}

From 15 August to 2 September 2009, sunset was between 1853 and 1724 UTC and sunrise between 0439 and 0539 UTC. ${ }^{222} \mathrm{Rn}$ concentration measurements at $0.1 \mathrm{~m}$ height are available for the hours terminating at 1800 UTC and at 0500 UTC. So during this period they are close to sunset and sunrise. The daily global radiation maxima ranged from 250 to $300 \mathrm{~W} \mathrm{~m}^{-2}$, increasing and decreasing smoothly from dawn to dusk, indicating clear-sky conditions. Exceptions are the 23, 24 and 30 August, when global radiation in midday showed substantial variations with intermittent abrupt falls to $100-150 \mathrm{~W} \mathrm{~m}^{-2}$. On 23 and 30 August total precipitation was 9.3 and $4.1 \mathrm{~mm}$, respectively; there was no precipitation during other days or nights. We assume that nights bracketed by clear-sky days (0500-1800 UTC) also had clear-sky conditions, an assumption supported by cloudiness data from the nearest $(15 \mathrm{~km})$ station. In our further analysis we will analyse the 14 nights (1800-0500 UTC) fulfilling this criterion. Nocturnal air temperature at $2.0 \mathrm{~m}$ height ranged from 27.9 to $9.0^{\circ} \mathrm{C}$ with an average value of $16.0^{\circ} \mathrm{C}$, while nocturnal wind speeds at $9.4 \mathrm{~m}$ height ranged from zero to $2.8 \mathrm{~m} \mathrm{~s}^{-1}$ with an average value of $0.8 \mathrm{~m} \mathrm{~s}^{-1}$. Values pooled by the same hour of day illustrate that ${ }^{222} \mathrm{Rn}$ accumulation begins around sunset and terminates with sunrise. Although air temperature and wind speed decrease already before sunset, ${ }^{222} \mathrm{Rn}$ concentrations at $6.5 \mathrm{~m}$ height only 

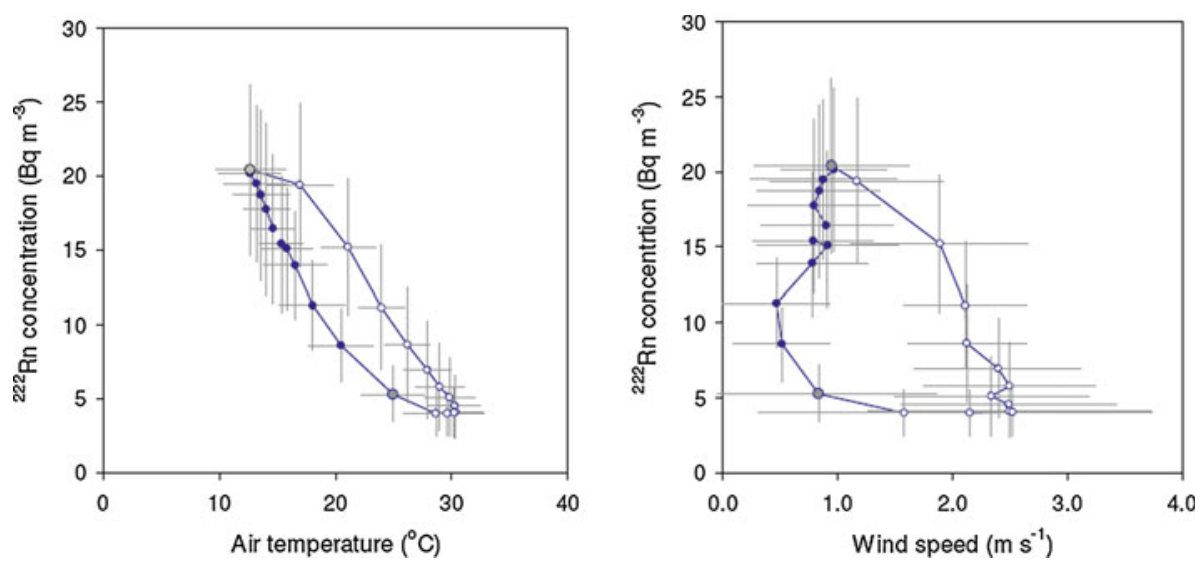

Fig. 1 Diurnal cycles (time progresses clockwise in 1-h steps between symbols): mean values for same hour of day during clear-sky conditions of atmospheric ${ }^{222} \mathrm{Rn}$ concentrations at $6.5 \mathrm{~m}$ height versus (left) air temperature at $2.0 \mathrm{~m}$ height, and (right) wind speed at $9.4 \mathrm{~m}$ height (open symbols for daytime and closed symbols for nighttime). Sunset and sunrise are indicated by grey dots. Error bars show \pm 1 standard deviation

start to substantially increase after sunset (Fig. 1). Strong cooling, light winds, a substantial increase in atmospheric ${ }^{222} \mathrm{Rn}$ concentrations, and presumably clear-sky conditions, point to the formation of a very stable boundary layer (vSBL) during the 14 selected nights.

We now postulate that stability lasts the entire period from sunset to sunrise, and verify this postulate by comparing accumulated ${ }^{222} \mathrm{Rn}$ with emitted ${ }^{222} \mathrm{Rn}$. Accumulated ${ }^{222} \mathrm{Rn}$ is estimated from the concentration increase between sunset and sunrise at $0.1 \mathrm{~m}$ height $\left(\Delta^{222} R n_{0.1 \mathrm{~m}}\right.$ ) and $6.5 \mathrm{~m}$ height $\left(\Delta^{222} R n_{6.5 \mathrm{~m}}\right.$ ), and the assumption of the vertical profile of accumulated ${ }^{222} \mathrm{Rn}$ to fit an exponential function $\left(R n_{z}=a e^{b z}\right.$, where $R n_{z}$ is the ${ }^{222} \mathrm{Rn}$ concentration at height $z$, and $\mathrm{a}$ and $\mathrm{b}$ are fitted parameters). This is the case if ${ }^{222} \mathrm{Rn}$ concentration profiles at sunset and at sunrise follow exponential functions, which is likely to be true (Stull 1988; Keller et al. 2010). The median $\Delta^{222} R n_{0.1 m}$ was $62.1 \mathrm{~Bq} \mathrm{~m}^{-3}$ and the median $\Delta^{222} R n_{6.5 m}$ was $14.8 \mathrm{~Bq} \mathrm{~m}^{-3}$ (Table 1). Average statistical counting errors associated with $\Delta^{222} R n_{0.1 m}$ are $\pm 7.4 \mathrm{Bqm}^{-3}$, and $\Delta^{222} R n_{6.5 m} \pm 0.2 \mathrm{~Bq} \mathrm{~m}^{-3}$. During the nights ending on 28 August and 1 September, the ${ }^{222} \mathrm{Rn}$ concentration did not change significantly at $0.1 \mathrm{~m}$ height but increased at $6.5 \mathrm{~m}$ by 9.0 and $10.0 \mathrm{~Bq} \mathrm{~m}^{-3}$, which is at the lower end of the observed $\Delta^{222} R n_{6.5 m}$. We will look at these two nights in more detail below. For the remaining 12 nights we fit an exponential function to $\Delta^{222} R n$ over height and integrate between the surface and infinite height. This generates values for the accumulated ${ }^{222} \mathrm{Rn}$ between 410 and $181 \mathrm{Bqm}^{-2}$ with a mean of $312 \mathrm{Bqm}^{-2}$ (s.d. $84 \mathrm{Bqm}^{-2}$ ). Flux density of ${ }^{222} \mathrm{Rn}$ did not differ significantly between nights, and on average it was $8.6 \mathrm{mBq} \mathrm{m}^{-2} \mathrm{~s}^{-1}$. The standard deviation between nights was $0.8 \mathrm{mBq} \mathrm{m}^{-2} \mathrm{~s}^{-1}$ and was largely due to errors associated with the ${ }^{222} \mathrm{Rn}$ counting statistics of the small ionization chamber. Hence, we can assume it remained the same during all 14 nights. A potentially larger uncertainty arises from the possibility that our ${ }^{222} \mathrm{Rn}$ flux measurement may not have been in a location that is representative of the larger source area. We believe that this is unlikely. The European ${ }^{222} \mathrm{Rn}$ flux map with $1^{\circ} \times 1^{\circ}$ resolution generated by Szegvary et al. (2009) indicates a mean annual flux density in the source area of $7.8 \mathrm{mBq} \mathrm{m}^{-2} \mathrm{~s}^{-1}$. Our measured value is $10 \%$ larger, which may be explained by the seasonally enhanced flux during summer because of relatively dry soil conditions (Szegvary et al. 2009). Accounting for the natural decay, no more than $328 \mathrm{~Bq} \mathrm{~m}^{-2}$ 
Table 1 Observed changes between sunset (1800 UTC) and sunrise (0500 UTC) during nights with strong cooling, light winds and clear-sky conditions: temperature at $2.0 \mathrm{~m}$ above ground $(\Delta T)$, atmospheric ${ }^{222} \mathrm{Rn}$ concentrations at $0.1 \mathrm{~m}\left(\Delta^{222} \mathrm{Rn}_{0.1 \mathrm{~m}}\right)$ and $6.5 \mathrm{~m}\left(\Delta^{222} \mathrm{Rn}_{6.5 \mathrm{~m}}\right)$ above ground

\begin{tabular}{|c|c|c|c|c|c|}
\hline \multirow[t]{2}{*}{ Date } & \multirow[t]{2}{*}{$\Delta T\left({ }^{\circ} \mathrm{C}\right)$} & \multicolumn{2}{|c|}{$\Delta^{222} \operatorname{Rn}\left(\mathrm{Bqm}^{-3}\right)$} & \multicolumn{2}{|c|}{ Accumulated ${ }^{222} \mathrm{Rn}\left(\mathrm{Bqm}^{-2}\right)$} \\
\hline & & $0.1 \mathrm{~m}$ & $6.5 \mathrm{~m}$ & Total & Below $6.5 \mathrm{~m}$ \\
\hline 16 Aug 2009 & -12.3 & 81.8 & 18.4 & 360 & 281 \\
\hline 17 Aug 2009 & -12.1 & 93.0 & 21.1 & 410 & 319 \\
\hline 18 Aug 2009 & -11.5 & 66.2 & 15.6 & 299 & 231 \\
\hline 19 Aug 2009 & -15.7 & 73.0 & 10.4 & 248 & 213 \\
\hline 20 Aug 2009 & -11.8 & 55.2 & 7.4 & 181 & 157 \\
\hline 21 Aug 2009 & -13.2 & 44.8 & 13.2 & 241 & 171 \\
\hline 22 Aug 2009 & -13.9 & 91.0 & 15.0 & 332 & 279 \\
\hline 26 Aug 2009 & -8.4 & 58.0 & 11.8 & 239 & 191 \\
\hline 27 Aug 2009 & -13.2 & 73.0 & 21.1 & 384 & 275 \\
\hline 28 Aug 2009 & -8.1 & -2.3 & 9.0 & - & - \\
\hline 29 Aug 2009 & -10.1 & 34.8 & 14.5 & 260 & 152 \\
\hline 1 Sep 2009 & -8.6 & -4.2 & 10.0 & - & - \\
\hline 2 Sep 2009 & -11.3 & 55.0 & 17.7 & 316 & 216 \\
\hline 3 Sep 2009 & -11.1 & 95.3 & 25.5 & 472 & 349 \\
\hline
\end{tabular}

Estimated amounts of ${ }^{222} \mathrm{Rn}$ accumulated during this period are based on the assumption of exponential ${ }^{222} \mathrm{Rn}$ concentration profiles around sunset and sunrise

would be expected to have accumulated between sunset and sunrise. Thus, an average of $95 \%$ (s.d. $26 \%$ ) of ${ }^{222} \mathrm{Rn}$ emitted from the ground during the night appears to have remained in the vSBL. This is an upper bound estimate because it is based on the integration from the ground to infinite height, which is obviously beyond the height of the vSBL. A lower bound estimate is the amount of ${ }^{222} \mathrm{Rn}$ accumulated between the surface and upper measurement height $(6.5 \mathrm{~m})$. Within this layer, $236 \mathrm{~Bq} \mathrm{~m}^{-2}$ (s.d. $64 \mathrm{~Bq} \mathrm{~m}^{-2}$ ) had accumulated, which is equal to $72 \%$ (s.d. 20\%) of ${ }^{222} \mathrm{Rn}$ emitted (Table 1). Consequently, the vSBL must have been very shallow and there was little loss of ${ }^{222} \mathrm{Rn}$ from it to the atmosphere above.

We are aware of only one other detailed observation in the vSBL where the data lend themselves to a similar interpretation. Lehmann et al. (2001) measured ${ }^{222} \mathrm{Rn}$ concentrations at four levels between the surface and $4.45 \mathrm{~m}$ height above a grassland in the Swiss plateau. During a '...very calm night in summer 2000 (Aug 19-Aug 20) when the meteorological and the soil conditions were stable (no wind, no rain)...', values in Lehmann et al. (2001) for $\Delta^{222} R n_{0.08 m}$ and $\Delta^{222} R n_{4.45 m}$ between 1800 and 0400 LT (local time) were around 85 and $30 \mathrm{~Bq} \mathrm{~m}^{-3}$, respectively. If we fit an exponential function and integrate between the surface and $6.5 \mathrm{~m}$ height we see that $286 \mathrm{~Bq} \mathrm{~m}^{-2}$ probably accumulated in this layer. Accounting for decay, this is $64 \%$ of the ${ }^{222} \mathrm{Rn}$ emitted during that night $\left({ }^{222} \mathrm{Rn}\right.$ flux density $=13.0 \mathrm{mBq} \mathrm{m}^{-2} \mathrm{~s}^{-1}$ ), so well within the range of our observations in the Carpathian Basin. Lehmann and Lehmann (1999) have analysed their data in a different way. They used the ${ }^{222} \mathrm{Rn}$ data together with data of the short-lived (half lifetime of $56 \mathrm{~s}$ ) ${ }^{220} \mathrm{Rn}$ isotope to estimate the near-surface turbulent diffusion coefficients $(K)$. Their estimate for $K$ at $0.2 \mathrm{~m}$ above ground $\left(K_{0.2 \mathrm{~m}}\right)$ was $5.9 \times 10^{-4} \mathrm{~m}^{2} \mathrm{~s}^{-1}$, assuming $K$ is constant with height, and $4.1 \times 10^{-4} \mathrm{~m}^{2} \mathrm{~s}^{-1}$, if $K$ was height-dependent. We can make a rough estimate for $K_{0.2 \mathrm{~m}}$ 

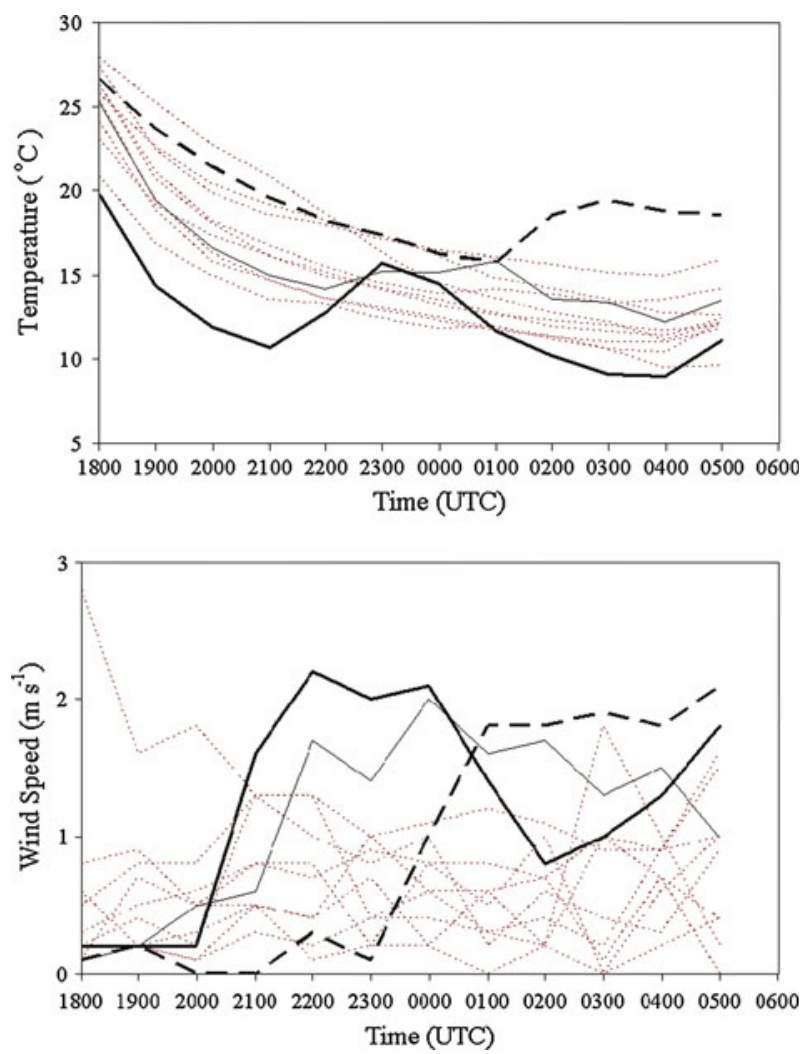

Fig. 2 Changes in (top) temperature at $2.0 \mathrm{~m}$ height, and (bottom) wind speed at $9.4 \mathrm{~m}$ height during the selected 14 nights. Thick lines indicate the two nights when ${ }^{222} \mathrm{Rn}$ at $0.1 \mathrm{~m}$ height around sunrise was not significantly different from that around the preceding sunset (dashed line 28 August; continuous line 1 September). Increases in temperature and wind speed on 19 August (thin continuous line) did not seem to have resulted in a loss of ${ }^{222} \mathrm{Rn}$ from the very stable boundary layer

in our study by assuming that the flux $(j)$ at $0.2 \mathrm{~m}$ height approximately equals the ${ }^{222} \mathrm{Rn}$ flux density at the surface measured with the accumulation chamber. From the exponential ${ }^{222} \mathrm{Rn}$ concentration profile fitted to our measurements at $0.1 \mathrm{~m}$ and $6.5 \mathrm{~m}$ height, we derive the ${ }^{222} \mathrm{Rn}$ concentration gradient at $0.2 \mathrm{~m}(\mathrm{~d} c / \mathrm{d} z)$. Values for $K_{0.2 m}$, calculated as $j /(\mathrm{d} c / \mathrm{d} z)$ ranged from $3.5 \times 10^{-4}$ to $1.9 \times 10^{-3} \mathrm{~m}^{2} \mathrm{~s}^{-1}$ with a median value of $5.6 \times 10^{-4} \mathrm{~m}^{2} \mathrm{~s}^{-1}$. This is very close to the much more sophisticatedly derived estimate by Lehmann and Lehmann (1999).

We now come back to the two nights when $\Delta^{222} R n_{0.1 m}$ was not significantly different from zero (28 August and 1 September). A closer look at the meteorological conditions shows the temperature at $2.0 \mathrm{~m}$ above the ground suddenly increased by about $5^{\circ} \mathrm{C}$ within two hours during the night (Fig. 2). An increase in wind speed at $9.4 \mathrm{~m}$ height preceded the temperature surge in both cases and lasted throughout the temperature disturbance. The disturbance are visible in the atmospheric ${ }^{222} \mathrm{Rn}$ decrease at $6.5 \mathrm{~m}$ level. Available meteorological information does not lend itself to a detailed analysis of the situation. However, we presume that larger atmospheric motions caused local thermal and shear instabilities resulting in wind gusts that reached to the ground and transported cold ${ }^{222} \mathrm{Rn}$-rich air above warm ${ }^{222} \mathrm{Rn}$-poor 
air, thereby inverting the ${ }^{222} \mathrm{Rn}$ concentration profile. Examples of large-scale motions that may lead to such a situation in the nocturnal boundary layer are density currents, solitary and internal waves (Sun et al. 2004). A similar but smaller such disturbance occurred on the night of 19 August (Fig. 2), but did not seem to have resulted in a loss of ${ }^{222} \mathrm{Rn}$ from the vSBL.

\section{Suggestions for Future Studies}

A more comprehensive future field campaign should include the following changes and additional measurements. Manual soil chamber measurements for at least one night at several locations around the site would decrease the uncertainty associated with the large-scale ${ }^{222} \mathrm{Rn}$ flux density. Also with little effort, the timing of atmospheric ${ }^{222} \mathrm{Rn}$ measurements at the lower level could be set closer to the times of sunset and sunrise. With more instrumentation available, wind speed and temperature should be measured at the same levels as atmospheric ${ }^{222} \mathrm{Rn}$ concentrations. Extending the measurement of meteorological parameters to a height likely to be above the vSBL, say to $40 \mathrm{~m}$, would be a next step. If instrumentation is available, measurements of vertical velocity variance and relative humidity at several levels would add significant information, to determine the Richardson number, $z / L$ and others. This would help quantify the impact of turbulent events.

\section{Conclusions}

${ }^{222} \mathrm{Rn}$ measurements at the K-puszta station in the Carpathian Basin during nights with strong cooling, light winds and clear skies provide evidence for a nearly complete decoupling of the very stable boundary layer (vSBL) from the atmosphere, lasting the entire period from sunset to sunrise. The shallow vSBL can be decoupled and isolated from the atmosphere above it. In a continental basin, interruption of this structure by what are probably larger scale atmospheric motions seems to be rare.

Acknowledgments This project was funded by the Swiss National Science Foundation (project no. 200020117622/1). We would like to thank the support from K-puszta station in Hungary for providing the meteorological data for the site and also cordially thank Endre Lowinger, Maria Kiss and Szilard Szoke for maintaining the installations at the station, for downloading data and for responding to our numerous little queries. A big thank you to Lukas Zimmermann for helping with transfer, set-up, de-installation and return of equipment brought from Basel to K-Puszta.

\section{References}

Banta RM, Mahrt L, Vickers D, Sun J, Balsley BB, Pichugina YL, Williams EJ (2007) The very stable boundary layer on nights with weak low-level jets. J Atmos Sci 64:3068-3090

Beyrich F (1994) Sodar observations of the stable boundary layer height in relation to the nocturnal low-level jet. Meteorol Z 3:29-34

Bowen BM, Baars JA, Stone GL (2000) Nocturnal wind direction shear and its potential impact on pollutant transport. J Appl Meteorol 39:437-445

Conen F, Neftel A, Schmid M, Lehmann BE (2002) N2O/Rn-222—soil flux calibration in the stable nocturnal surface layer. Geophys Res Lett. doi:10.1029/2001GL013429

Haszpra L (1998) Atmospheric $\mathrm{CO}_{2}$ record from in situ measurements at K-puszta, Hungary. In: Trends: a compendium of data on global change. Carbon Dioxide Information Analysis Center, Oak Ridge National Laboratory, U.S. Department of Energy, Oak Ridge, TN, USA 
Keller CA, Huwald H, Vollmer MK, Wenger A, Hill M, Reimann S (2010) Fiber optic distributed temperature sensing fort he determination of the nocturnal atmospheric boundary layer height. Atmos Meas Tech Discuss 3:2723-2741. doi:10.5194/amtd-3-2723-2010

Lehmann BE, Lehmann M (1999) Radon-220 calibration of near-surface turbulent gas transport. Geophys Res Lett 26:607-610

Lehmann BE, Neftel A, Tarakanov SV (2001) Continuous on-line calibration of diffusive soil-atmosphere trace gas transport using vertical ${ }^{220} \mathrm{Rn}$ - and ${ }^{222} \mathrm{Rn}$-activity profiles. Radiochim Acta 89:839-843

Lehmann BE, Ihly B, Salzmann S, Conen F, Simon E (2004) An automatic static chamber for continuous $\mathrm{Rn}-220$ and Rn-222 flux measurements from soil. Radiat Meas 38:43-50

Mahrt L (1998) Stratified atmospheric boundary layers and breakdown of models. Theor Comput Fluid Dyn 11:263-279

Malhi Y (1995) The significance of the dual solutions for heat fluxes measured by the temperature fluctuation method in stable conditions. Boundary-Layer Meteorol 74:389-396

Moriizumi J, Nagamine K, Iida T, Ikebe Y (1996) Estimation of areal flux of atmospheric methane in an urban area of Nagoya, Japan, inferred from atmospheric radon-222 data. Atmos Environ 30:1543-1549

Oyha Y, Neff DE, Meroney RN (1997) Turbulence structure in a stratified boundary layer under stable conditions. Boundary-Layer Meteorol 83:139-161

Salmond JA, McKendry IG (2005) A review of turbulence in the very stable nocturnal boundary layer and its implications for air quality. Prog Phys Geogr 29(2):171-188

Stull RB (1988) An introduction to boundary layer meteorology. Kluwer, Dordrecht, 666 pp

Sun J, Lenschow DH, Burns SP, Banta RM, Newsom RK, Coulter R, Frasier S, Ince T, Nappo C, Balsley BB, Jensen M, Mahrt L, Miller D, Skelly B (2004) Atmospheric disturbances that generate intermittent turbulence in nocturnal boundary layers. Boundary-Layer Meteorol 110:255-279

Szegvary T, Conen F, Ciais P (2009) European 222Rn inventory for applied atmospheric studies. Atmos Environ 43:1536-1539

Whittlestone S, Zahorowski W (1998) Baseline radon detectors for shipboard use: Development and deployment in the First Aerosol Characterization Experiment (ACE 1). J Geophys Res 103(D13): 16743-16751

Wilson SR, Dick AL, Fraser PJ, Whittlestone S (1997) Nitrous oxide flux estimates for south-eastern Australia. J Atmos Chem 26:169-188 